\title{
Identification of Sympathetic Premotor Neurons in Medullary Raphe Regions Mediating Fever and Other Thermoregulatory Functions
}

\author{
Kazuhiro Nakamura, ${ }^{1}$ Kiyoshi Matsumura, ${ }^{2}$ Thomas Hübschle, ${ }^{4}$ Yoshiko Nakamura, ${ }^{2}$ Hiroyuki Hioki, ${ }^{1}$ \\ Fumino Fujiyama, ${ }^{1}$ Zsolt Boldogköi, ${ }^{6}$ Matthias König, ${ }^{5}$ Heinz-Jürgen Thiel, ${ }^{5}$ Rüdiger Gerstberger, ${ }^{4}$ Shigeo Kobayashi, ${ }^{2}$ \\ and Takeshi Kaneko ${ }^{1,3}$ \\ ${ }^{1}$ Department of Morphological Brain Science, Graduate School of Medicine, ${ }^{2}$ Department of Intelligence Science and Technology, Graduate School of \\ Informatics, and ${ }^{3}$ Core Research for Evolution Science and Technology, Japan Science and Technology, Kyoto University, Kyoto 606-8501, Japan, Institutes \\ of ${ }^{4}$ Veterinary-Physiology and ${ }^{5}$ Virology, Justus-Liebig-University, D-35392 Giessen, Germany, and ${ }^{6}$ Department of Medical Biology, Faculty of Medicine, \\ University of Szeged, Szeged H-6720, Hungary
}

Sympathetic premotor neurons directly control sympathetic preganglionic neurons (SPNs) in the intermediolateral cell column (IML) of the thoracic spinal cord, and many of these premotor neurons are localized in the medulla oblongata. The rostral ventrolateral medulla contains premotor neurons controlling the cardiovascular conditions, whereas rostral medullary raphe regions are a candidate source of sympathetic premotor neurons for thermoregulatory functions. Here, we show that these medullary raphe regions contain putative glutamatergic neurons and that these neurons directly control thermoregulatory SPNs. Neurons expressing vesicular glutamate transporter 3 (VGLUT3) were distributed in the rat medullary raphe regions, including the raphe magnus and rostral raphe pallidus nuclei, and mostly lacked serotonin immunoreactivity. These VGLUT3-positive neurons expressed Fos in response to cold exposure or to central administration of prostaglandin $\mathrm{E}_{2}$, a pyrogenic mediator. Transneuronal retrograde labeling after inoculation of pseudorabies virus into the interscapular brown adipose tissue (BAT) or the tail indicated that those VGLUT3-expressing medullary raphe neurons innervated these thermoregulatory effector organs multisynaptically through SPNs of specific thoracic segments, and microinjection of glutamate into the IML of the BAT-controlling segments produced BAT thermogenesis. An anterograde tracing study further showed a direct projection of those VGLUT3-expressing medullary raphe neurons to the dendrites of SPNs. Furthermore, intra-IML application of glutamate receptor antagonists blocked BAT thermogenesis triggered by disinhibition of the medullary raphe regions. The present results suggest that VGLUT3-expressing neurons in the medullary raphe regions constitute excitatory neurons that could be categorized as a novel group of sympathetic premotor neurons for thermoregulatory functions, including fever.

Key words: fever; glutamate; premotor neuron; prostaglandin $\mathrm{E}_{2}$; raphe; sympathetic nervous system; thermoregulation; vesicular glutamate transporter

\section{Introduction}

Sympathetic premotor neurons play an important role in the supraspinal autonomic nervous system by sending command signals directly to sympathetic preganglionic neurons (SPNs) in the intermediolateral cell column (IML) of the thoracic spinal cord. SPNs, in turn, make outputs leading to stimulation of peripheral effector organs. These bulbospinal premotor pathways are thought to mediate the regulation of blood circulation, body temperature,

\footnotetext{
Received April 1, 2004; revised April 30, 2004; accepted May 3, 2004.

This work was supported by Grants-in-Aid for Scientific Research (12308039, 13470011, 14580728, 14657015 , 15029224, and 16200025) and Special Coordination Funds for Promoting Science and Technology from the Ministry of Education, Culture, Sports, Science and Technology of Japan. K.N. is a Research Fellow of the Japan Society for the Promotion of Science (no. 3814). We are grateful to Dr. Takahiro Furuta, Kouichi Nakamura, and Dr. Nobuaki Tamamaki for providing Sindbis virus and anti-EGFP antibody.

Correspondence should be addressed to Dr. Kazuhiro Nakamura, Department of Morphological Brain Science, Graduate School of Medicine, Kyoto University, Sakyo-ku, Kyoto 606-8501, Japan. E-mail: kazu@mbs.med.kyoto-u.ac.jp. D0l:10.1523/JNEUROSCI.1219-04.2004

Copyright $\odot 2004$ Society for Neuroscience $\quad 0270-6474 / 04 / 245370-11 \$ 15.00 / 0$
}

metabolism, and other diverse homeostatic functions. The focus of many studies on sympathetic premotor control has been brought into the regulation of the cardiovascular system (Dampney, 1994). Of the known cardiovascular-regulating brain regions, the rostral ventrolateral medulla (RVLM) is the most established region to contain sympathetic premotor neurons that play a crucial role in the control of arterial blood pressure (Dampney, 1994). However, RVLM premotor activity scarcely contributes to the control of other effector organs, such as the pupil, nictitating membrane, gut, brown adipose tissue (BAT), and rat tail artery (McAllen et al., 1982; McAllen, 1986b; Morrison, 1999; Rathner and McAllen, 1999).

The rostral medullary raphe regions consisting of the rostral part of the raphe pallidus nucleus $(\mathrm{rRPa})$ and the raphe magnus nucleus (RMg) have been considered as a possible sympathetic premotor region involved in thermoregulation. Stimulation of these regions increased the sympathetic activity of thermoregulatory effector organs, such as rat interscapular BAT, rat tail artery, and rabbit ear pinna blood vessels (Blessing et al., 1999; 
Morrison, 1999; Morrison et al., 1999; Rathner and McAllen, 1999; Blessing and Nalivaiko, 2001). Furthermore, neurons in these raphe regions were activated by cold exposure and central administration of prostaglandin (PG) $\mathrm{E}_{2}$, an endogenous pyrogenic mediator (Bonaz and Taché, 1994; Morrison et al., 1999; Nakamura et al., 2002), and suppression of these regions abolished sympathetic BAT thermogenesis and fever triggered by central $\mathrm{PGE}_{2}$ administration (Nakamura et al., 2002; Morrison, 2003). In addition, these raphe regions are known to contain IML-projecting neurons (Loewy, 1981), a part of which were activated by cold exposure (Rathner et al., 2001). However, by lack of any suitable markers to identify thermoregulatory neurons in these raphe regions, we have no clear-cut functional neuroanatomical characterization of these neurons. Furthermore, such markers would directly prove the existence of raphe sympathetic premotor neurons serving thermoregulatory functions.

We have recently reported that SPNs receive inputs by at least two populations of axon terminals positive for vesicular glutamate transporter (VGLUT) 2 and VGLUT3 (Nakamura et al., 2004), which accumulate glutamate into synaptic vesicles (Fremeau et al., 2002; Gras et al., 2002; Kaneko and Fujiyama, 2002; Schäfer et al., 2002; Takamori et al., 2002). The VGLUT2positive terminals are likely provided from cardiovascular RVLM sympathetic premotor neurons, but neurons in and around the rRPa are mostly negative for VGLUT2 (Stornetta et al., 2002a,b). Thus, we hypothesized that VGLUT3-expressing neurons in the rostral medullary raphe regions exert premotor functions in the sympathetic thermoregulatory system. To test this hypothesis, we histochemically and physiologically investigated VGLUT3expressing neurons in medullary raphe regions with a special focus on their functional properties as sympathetic premotor neurons mediating fever and other thermoregulatory functions.

\section{Materials and Methods}

Animals. Seventy male Wistar rats (200-300 gm) were used in the present study. They were housed three or four to a cage with ad libitum access to food and water in a room air-conditioned at $26 \pm 2^{\circ} \mathrm{C}$ with a standard 12 $\mathrm{hr}$ light/dark cycle. All experiments were performed in accordance with the rules of animal care by the Institute of Laboratory Animals, Faculty of Medicine, Kyoto University.

Central $P G E_{2}$ administration. The left lateral ventricle of rats was cannulated as described previously (Nakamura et al., 2002). The animals were kept for at least 1 week to recover. One day before $\mathrm{PGE}_{2}$ administration, the stainless steel cannula was flushed with pyrogen-free $0.9 \%$ saline (Otsuka, Tokyo, Japan). On the day of $\mathrm{PGE}_{2}$ administration, the animals were anesthetized with urethane $(1.3 \mathrm{gm} / \mathrm{kg}$, i.p.; Sigma, St. Louis, MO) between 10:00 and 11:00 A.M. and left on a self-regulating heating pad (KN-474; Natume, Tokyo, Japan) to stabilize the rectal temperature $\left(\mathrm{T}_{\text {rec }}\right)$ at $37^{\circ} \mathrm{C}$. The $\mathrm{T}_{\text {rec }}$ was monitored with a copperconstantan thermocouple inserted into the rectum through the anus. Four hours later, $\mathrm{PGE}_{2}$ (500 ng; Sigma) in $15 \mu$ l of pyrogen-free $0.9 \%$ saline or only saline was injected into the ventricle through the cannula. After $1 \mathrm{hr}$ of $\mathrm{T}_{\text {rec }}$ recording, the animals were immediately fixed transcardially and the brains were subjected to immunohistochemistry for Fos and VGLUT3.

Cold exposure. Cold exposure of rats was performed in a climate chamber. Animals were placed individually in plastic cages with wire mesh lids with ad libitum access to food and water. To acclimatize the animals to the climate chamber, they were placed in the chamber air-conditioned at $24^{\circ} \mathrm{C}$ for $2 \mathrm{hr}$ once per day (from 10:00 A.M. to 12:00 P.M.), and this training was continued for $3 \mathrm{~d}$. On the fourth day, they were exposed to $4^{\circ} \mathrm{C}$ for $4 \mathrm{hr}$ (from 10:00 A.M. to 2:00 P.M.). Control animals were exposed to $24^{\circ} \mathrm{C}$ for $4 \mathrm{hr}$ on the fourth day. The temperature and duration of cold exposure followed the protocol of a previous study (Morrison et al., 1999). After the exposure, the animals were immediately fixed transcardially and the brains were subjected to Fos and VGLUT3 immunohistochemistry.
Inoculation of pseudorabies virus. The propagation of the attenuated Bartha strain of pseudorabies virus (PRV) was described previously (Yoshida et al., 2003). Rats under sedation with medetomidine hydrochloride $(0.3 \mathrm{mg} / \mathrm{kg}$, i.m.; Domitor; Pfizer, Karlsruhe, Germany) were anesthetized deeply with ketamine hydrochloride $(150 \mathrm{mg} / \mathrm{kg}$, i.p.; Bayer, Leverkusen, Germany). The interscapular BAT was exposed, and the PRV solution $\left(1 \times 10^{8.03} \mathrm{TCID}_{50} / \mathrm{ml}\right)$ was injected at three different sites (1 $\mu \mathrm{l}$ each) of the left BAT pad with a Hamilton syringe (Hamilton, Bonaduz, Switzerland). For PRV inoculation into the tail, the virus solution was injected by puncturing from the skin surface at eight different sites $(0.5 \mu \mathrm{l} \mathrm{each})$ on the left side of the ventral tail artery within $\sim 2 \mathrm{~cm}$ from the tail base. The needle was kept in place for $30 \mathrm{sec}$, and any efflux from the point of puncture was immediately absorbed with sterile cotton buds. After the injections into the BAT, the wound was closed. For rapid reversal of the anesthetic, atipamezole hydrochloride $(2.5 \mathrm{mg} / \mathrm{kg}$, i.m.; Antisedan; Pfizer) was administered. The animals were allowed to survive up to $70 \mathrm{hr}$ for BAT-inoculated animals and $121 \mathrm{hr}$ for tailinoculated ones and then were fixed for immunohistochemical procedures.

Sindbis virus injection. For anterograde tracing studies, we used a replication-deficient recombinant Sindbis virus containing a gene encoding enhanced green fluorescent protein (EGFP) tagged with the $\mathrm{N}$-terminal palmitoylation signal sequence of growth-associated protein-43 (Moriyoshi et al., 1996) that is driven by a subgenomic promoter of the virus for expression in mammalian cells (Furuta et al., 2001). Rats were anesthetized deeply with chloral hydrate $(280 \mathrm{mg} / \mathrm{kg}$, i.p. $)$ and placed in a stereotaxic apparatus (David Kopf Instruments, Tujunga, CA). The virus solution $\left(0.1-0.5 \mu \mathrm{l} ; 2 \times 10^{10}\right.$ infectious unit $\left./ \mathrm{ml}\right)$ was pressure-injected into the $\mathrm{rPa}$ and $\mathrm{RMg}$ through a glass micropipette (tip inner diameter, 15-20 $\mu \mathrm{m}$ ) with the aid of a Picospritzer II (General Valve, Fairfield, NJ). The coordinates for the injection site were $2.3 \mathrm{~mm}$ posterior to the interaural line, on the midline, and 9.3-9.5 $\mathrm{mm}$ ventral to the brain surface. Eighteen hours after the injection, animals were reanesthetized and fixed as described below.

Immunohistochemistry. Immunohistochemical procedures were based on our previous studies (Nakamura et al., 2000, 2001). The rats treated as described above were perfused transcardially with $100-150 \mathrm{ml}$ of $50 \mathrm{mM}$ PBS, followed by $200-300 \mathrm{ml}$ of $2 \%$ formaldehyde or paraformaldehyde in $0.1 \mathrm{M}$ phosphate buffer, $\mathrm{pH}$ 7.4. The brain and spinal cord were removed and postfixed in the same fixative at $4^{\circ} \mathrm{C}$ for $2 \mathrm{hr}$, cryoprotected with $30 \%$ sucrose solution, and cut into 20 - $\mu \mathrm{m}$-thick sections on a freezing microtome.

The sections were incubated overnight with $0.5 \mu \mathrm{g} / \mathrm{ml}$ anti-VGLUT3 guinea pig antibody (Hioki et al., 2004) and then for $1 \mathrm{hr}$ with $10 \mu \mathrm{g} / \mathrm{ml}$ biotinylated donkey antibody to guinea pig IgG (Jackson ImmunoResearch, West Grove, PA). The sections were further incubated for $1 \mathrm{hr}$ with avidin-biotinylated peroxidase complex (ABC-Elite; 1:50; Vector Laboratories, Burlingame, CA). Bound peroxidase was visualized by incubation of the sections with $0.02 \%$ DAB (Dojindo, Kumamoto, Japan), $0.0002 \%$ hydrogen peroxide, and $0.5 \%$ ammonium nickel sulfate hexahydrate in $50 \mathrm{~mm}$ Tris-HCl, pH 7.6, to develop VGLUT3 immunoreactivity as a blue-black reaction product of Ni-DAB. For double immunoperoxidase staining of VGLUT3 and Fos, the bound peroxidase and unreacted avidin and biotin in the sections were blocked with $3 \%$ hydrogen peroxide and an avidin-biotin blocking kit (Vector Laboratories), respectively. The sections were further incubated overnight with an antiFos rabbit serum (1:20,000; Ab-5; Oncogene, Cambridge, MA). After the sections were incubated with a biotinylated donkey antibody to rabbit IgG (10 $\mu \mathrm{g} / \mathrm{ml}$; Chemicon, Temecula, CA) and then with ABC-Elite, the bound peroxidase was visualized by incubating the sections with $0.02 \%$ $\mathrm{DAB}$ and $0.001 \%$ hydrogen peroxide in $50 \mathrm{~mm}$ Tris- $\mathrm{HCl}, \mathrm{pH}$ 7.6. In this manner, Fos immunoreactivity was developed as a brown reaction product of DAB. By omitting one of the primary antibodies, we confirmed that there was no cross-reactivity between the reagents involved in the two different immunoperoxidase staining steps. For absorption test for VGLUT3 immunoreactivity, the VGLUT3 antibody was incubated with a 10,000 -fold (molar ratio) excess amount of the antigenic peptide for the antibody (Hioki et al., 2004) for $1 \mathrm{hr}$ prior to the incubation with sections. 
For double immunofluorescence staining, sections were incubated overnight with a mixture of an anti-VGLUT3 guinea pig antibody (0.1 $\mu \mathrm{g} / \mathrm{ml})$ and an anti-serotonin rabbit serum (1:5000; Sigma) or an antiPRV rabbit antibody ( $1 \mu \mathrm{g} / \mathrm{ml}$; Affinity Bioreagents, Golden, CO). The sections were incubated for $1 \mathrm{hr}$ with $10 \mu \mathrm{g} / \mathrm{ml}$ biotinylated donkey antibody to guinea pig IgG and then blocked for $30 \mathrm{~min}$ with $10 \%$ normal guinea pig serum. Under the presence of the normal serum, the sections were further incubated for $1 \mathrm{hr}$ with $10 \mu \mathrm{g} / \mathrm{ml}$ Alexa594-conjugated goat antibody to rabbit IgG (Molecular Probes, Eugene, OR) and then for $1 \mathrm{hr}$ with ABC-Elite (1:50). Peroxidase reaction was finally performed by incubating the sections with fluorescein-conjugated tyramide (Tyramide Signal Amplification fluorescence systems; 1:50; PerkinElmer Life Sciences, Boston, MA) for $5 \mathrm{~min}$. The sections were washed thoroughly and mounted onto gelatin-coated glass slides. For double fluorescence microscopy, an epifluorescence microscope (Axioplan 2; Zeiss, Oberkochen, Germany) was used with an appropriate filter set for fluorescein (excitation, $450-490 \mathrm{~nm}$; emission, $515-565 \mathrm{~nm}$ ) or Alexa 594 (excitation, 530-585 nm; emission, $\geq 615 \mathrm{~nm}$ ).

For triple immunofluorescence staining, spinal cord sections were incubated overnight with a mixture of an anti-VGLUT3 guinea pig antibody $(0.5 \mu \mathrm{g} / \mathrm{ml})$, an anti-EGFP rabbit antibody $(0.1 \mu \mathrm{g} / \mathrm{ml})$ (Tamamaki et al., 2000) and an anti-ChAT goat antibody (1:200; Chemicon). The sections were incubated for $1 \mathrm{hr}$ with $10 \mu \mathrm{g} / \mathrm{ml}$ biotinylated donkey antibody to goat IgG (Chemicon) and then blocked for $30 \mathrm{~min}$ with $10 \%$ normal goat serum. Under the presence of the normal serum, the sections were further incubated for $1 \mathrm{hr}$ with $10 \mu \mathrm{g} / \mathrm{ml}$ Alexa546-conjugated goat antibody to guinea pig IgG, $10 \mu \mathrm{g} / \mathrm{ml}$ Alexa488-conjugated goat antibody to rabbit IgG, and $5 \mu \mathrm{g} / \mathrm{ml}$ Alexa647-conjugated streptavidin (Molecular Probes). The sections were observed under a confocal laserscanning microscope (LSM 5 PASCAL; Zeiss).

Anatomy and cell counting. Most of the cytoarchitecture and nomenclature in the present study followed those of the brain atlas by Paxinos and Watson (1998). The raphe pallidus nucleus was nomenclaturally divided into two parts: rostral $(\mathrm{rRPa})$ and caudal $(\mathrm{cRPa})$ to the rostral end of the inferior olivary complex (IO) (Nakamura et al., 2002).

The number of immunolabeled cell bodies was counted in every six $20-\mu \mathrm{m}$-thick frontal sections of the medulla oblongata over the rostrocaudal levels at which VGLUT3-immunoreactive cells were distributed: from the rostral end of the facial nucleus to the caudal end of the fourth ventricle. The cell number was collected from five ventral medullary regions: $\mathrm{RMg}$ and parapyramidal region (PPy); rRPa; raphe obscurus nucleus (ROb) and ventral part of the gigantocellular reticular nucleus (Giv); cRPa; and a zone near the ventral surface of the pyramidal tract. The RMg, PPy, and rRPa are located rostral to the rostral end of the IO, and the ROb, Giv, and cRPa are caudal to that. A zone near the ventral surface of the pyramidal tract was not divided rostrocaudally.

In situ hybridization. Nonradioactive in situ hybridization was performed as described previously (Hioki et al., 2004). The antisense and sense probes for VGLUT3 were 619 nucleotides in length. Hybridization using the sense probe did not show any signals.

Monitoring BAT thermogenesis. Rats anesthetized with urethane (1.3 $\mathrm{gm} / \mathrm{kg}$, i.p.) were positioned in a stereotaxic apparatus (Narishige, Tokyo, Japan), and the thoracic spinal cord was exposed. For injection of reagents into the $\mathrm{rRPa}$, the cranium on the cerebellum was further removed. For the spinal cord exposure, the damage to the interscapular BAT was restricted to the right pad, whereas the left one was kept intact, and a copper-constantan thermocouple was inserted into the left pad to monitor the BAT temperature $\left(\mathrm{T}_{\mathrm{BAT}}\right)$. The animals were placed on a self-regulating heating pad to stabilize the $\mathrm{T}_{\text {rec }}$ at $37^{\circ} \mathrm{C}$ in a chamber air-conditioned at $25-27^{\circ} \mathrm{C}$ for $2 \mathrm{hr}$.

For glutamate microinjection into the IML, a glutamate monosodium salt solution $(0.5 \mathrm{M}, \mathrm{pH} 7.2-7.4,40 \mathrm{nl})$ containing $0.1 \%$ fluorescent microspheres with a diameter of $0.1 \mu \mathrm{m}$ (Molecular Probes) or its vehicle alone was unilaterally microinjected at three sites in the left IML of the T3-T5 segments (one injection per segment) through a glass micropipette (tip inner diameter, $20-30 \mu \mathrm{m}$ ) with the aid of a microinjector (Nanoject II/Micro 4 system; World Precision Instruments, Sarasota, $\mathrm{FL})$. The injections were completed within $2 \mathrm{~min}$. The coordinates for the IML were $0.5 \mathrm{~mm}$ lateral to the midline and $1.0 \mathrm{~mm}$ ventral to the dorsal surface of the spinal cord. The dose of glutamate was chosen on the basis of previous studies (McAllen, 1986a; Madorin and Calaresu, 1994). After $30 \mathrm{~min}$ of $\mathrm{T}_{\mathrm{BAT}}$ recording, the animals were decapitated.

For injection of glutamate receptor antagonists into the IML, a mixture of AP-5 (5 mM; Sigma) and CNQX (5 mm; Sigma), dissolved in pyrogen-free $0.9 \%$ saline containing fluorescent microspheres, or its vehicle alone was injected into the IML on both sides of the T2-T6 spinal segments through a glass micropipette (tip inner diameter, $30-40 \mu \mathrm{m}$ ) with the aid of the microinjector. The distribution of VGLUT3-positive synapses is not limited to the IML but also extends into the lateral funiculus and intercalated nucleus (Nakamura et al., 2004). To cover these synapses, the injections were made with an interval of $0.8-1.0 \mathrm{~mm}$ along the rostrocaudal axis with a volume of $200 \mathrm{nl} /$ site. Five minutes after the completion of the injections, (-)-bicuculline methochloride (1 mM, 200 $\mathrm{nl}$; Sigma) dissolved in pyrogen-free $0.9 \%$ saline containing fluorescent microspheres was injected through a silica capillary (inner diameter, 75 $\mu \mathrm{m}$; outer diameter, $150 \mu \mathrm{m}$ ) into the $\mathrm{rRPa}$ as described in our previous report (Nakamura et al., 2002). After $1 \mathrm{hr}$ of $\mathrm{T}_{\mathrm{BAT}}$ recording, the animals were decapitated.

After the recording, the spinal cord and brain were removed, frozen, and sectioned at a thickness of $40 \mu \mathrm{m}$ with a cryostat. After the sections were stained with toluidine blue, the location of the microinjections was identified by detecting the fluorescent microspheres under an epifluorescence microscope (Eclipse E600; Nikon, Tokyo, Japan).

Data analysis. All data are presented as the means \pm SEM. Statistical analysis was performed using the unpaired Student's $t$ test (Instat 2.00; Graph Pad, San Diego, CA), and a result was considered significant given a $p$ value of $<0.05$.

\section{Results}

\section{Expression of VGLUT3 in medullary raphe regions}

There is no observation report of VGLUT3-expressing neurons in the medulla oblongata. To investigate the expression of VGLUT3, we performed immunohistochemistry with an antibody to VGLUT3 because this transporter is localized in cell bodies as well as axon terminals (Fremeau et al., 2002; Gras et al., 2002; Schäfer et al., 2002), and we have shown that all the VGLUT3-immunoreactive cell bodies found in the cerebral cortex exhibited hybridization signals for VGLUT3 mRNA (Hioki et al., 2004). VGLUT3-immunoreactive cell bodies were found in medullary raphe regions (Fig. 1a) over rostrocaudal levels between the rostral end of the facial nucleus and the caudal end of the fourth ventricle. The distribution of VGLUT3-immunoreactive neurons was dense in the caudal one third of the rRPa, RMg, and PPy (Fig. 1e, interaural $-2.30 \mathrm{~mm}$ ) but sparse in these nuclei at the level of the rostral end of the facial nucleus (Fig. 1e, interaural $-1.30 \mathrm{~mm}$ ) and in caudal medullary raphe regions, such as the $\mathrm{cRPa}, \mathrm{ROb}$, and Giv (Fig. 1e, interaural $-3.30 \mathrm{~mm}$ ). It is noted that VGLUT3immunoreactive neurons were distributed also near the ventral surface of the pyramidal tract, especially just rostral to the rostral end of the IO (Fig. 1e, interaural $-2.30 \mathrm{~mm}$ ). No or very few VGLUT3immunoreactive cells were found in the other regions of the medulla oblongata. VGLUT3 immunoreactivity was completely abolished by preabsorption of the primary antibody with the antigenic peptide (Fig. 1b). In situ hybridization analysis visualized neurons expressing VGLUT3 mRNA in medullary raphe regions (Fig. 1c), and the distribution was similar to that observed in VGLUT3 immunohistochemistry.

We next examined whether the VGLUT3-expressing neurons were serotonergic or not, because the raphe regions are rich in serotonergic neurons. Double immunofluorescence staining showed that most VGLUT3-immunoreactive medullary raphe neurons were negative for serotonin immunoreactivity (Fig. $1 d, e$ ). In a quantitative analysis, serotonin immunoreactivity was exhibited by only 9\% (29 of 324) of VGLUT3-immunoreactive neurons in the RMg 

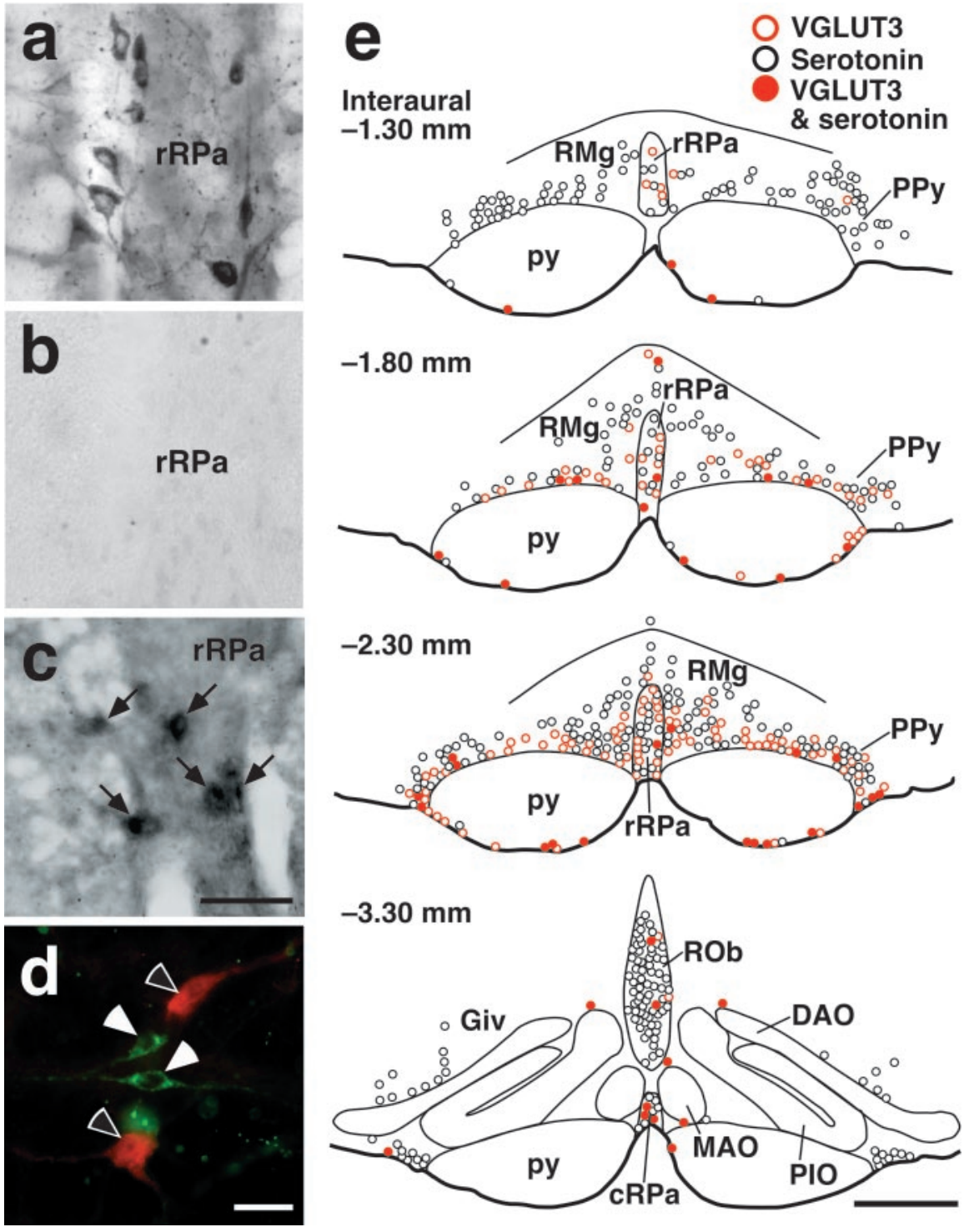

Figure 1. Expression of VGLUT3 in medullary raphe neurons. $a$, Immunoperoxidase staining for VGLUT3 in medullary raphe regions. VGLUT3 immunoreactivity was localized in neuronal cell bodies as well as fibers and terminals. $b$, No immunoreactivity was observed after preincubation of the anti-VGLUT3 antibody with the antigenic peptide. c, In situ hybridization for VGLUT3 mRNA in medullary raphe regions. Hybridization signals for VGLUT3 mRNA were exhibited by medullary raphe neurons (arrows). $d$, Double immunofluorescence labeling for VGLUT3 (green) and serotonin (red) in medullary raphe regions. VGLUT3immunoreactive neurons (filled arrowheads) and serotonin-immunoreactive neurons (open arrowheads) were clearly visualized. $e$, Brain maps showing the distribution of VGLUT3-immunoreactive neurons and serotonin-immunoreactive ones. Immunoreactive cell bodies in a $20-\mu \mathrm{m}$-thick frontal section of the corresponding rostrocaudal position were plotted on a drawing. DA0, Dorsal accessory olivary nucleus; $\mathrm{MAO}$, medial accessory olivary nucleus; $\mathrm{PIO}$, principal inferior olivary nucleus; py, pyramidal tract. Scale bars: $a-c$ (in c), $50 \mu \mathrm{m} ; d, 30 \mu \mathrm{m} ; e, 500 \mu \mathrm{m}$.

and $\mathrm{PPy}, 14 \%$ (10 of 71 ) in the rRPa, and 30\% (30 of 99) in the zone near the ventral surface of the pyramidal tract. Although the number of VGLUT3-immunoreactive neurons was low in caudal medullary raphe regions, double-labeled neurons were frequently found: 21 of 45 in the ROb and Giv and 17 of 20 in the $\mathrm{CRPa}$.

\section{Activation of VGLUT3-expressing medullary raphe neurons} by thermogenic stimuli

We have previously reported that central administration of $\mathrm{PGE}_{2}$ activates neurons in the rRPa and $\mathrm{RMg}$ and that neuronal activation in these regions is essential for $\mathrm{PGE}_{2}$-induced sympathetic BAT thermogenesis and fever (Nakamura et al., 2002). Furthermore, exposure of animals to cold environment, which also trig- gers sympathetic thermogenesis, has been shown to activate neurons in similar regions (Bonaz and Taché, 1994; Morrison et al., 1999). Thus, we hypothesized that the activation induced by these thermogenic stimuli is caused in the VGLUT3expressing neuronal population. To test this hypothesis, we immunohistochemically examined the expression of Fos, a widely used protein marker for activated neurons (Sagar et al., 1988), in VGLUT3immunoreactive medullary raphe neurons in response to central administration of $\mathrm{PGE}_{2}$ or to cold exposure $\left(4^{\circ} \mathrm{C}\right)$. Intracerebroventricular $\mathrm{PGE}_{2}$ injection caused a significant rise in $\mathrm{T}_{\mathrm{rec}}$ (fever) (2.8 \pm $0.1^{\circ} \mathrm{C}$ in $\mathrm{PGE}_{2}$-injected rats, $n=4$; $0.067 \pm 0.03^{\circ} \mathrm{C}$ in saline-injected rats, $n=$ $3 ; p<0.0001)$ and induced Fos expression in VGLUT3-immunoreactive neurons in medullary raphe regions (Fig. 2a,c). Cold exposure also induced Fos expression in VGLUT3-immunoreactive medullary raphe neurons, compared with exposure to thermoneutral temperature $\left(24^{\circ} \mathrm{C}\right.$ ) (Fig. $2 b$ ). The overall distribution pattern of Fos-expressing medullary cells in coldexposed rats was similar to that observed in $\mathrm{PGE}_{2}$-injected ones. As shown quantitatively (Fig. 3), a drastic increase in the percentage of Fos expression in VGLUT3immunoreactive neurons by these thermogenic stimuli was observed in rostral medullary raphe regions: the RMg and PPy (11.2fold by $\mathrm{PGE}_{2}$ injection and 22.1-fold by cold exposure), the rRPa (8.9- and 21.3-fold), and the ventral surface of the pyramidal tract (8.7- and 4.1-fold). The excitatory effect by these stimuli was less pronounced in caudal medullary raphe regions: the $\mathrm{ROb}$ and Giv (2.2- and 5.0-fold) and cRPa (2.4- and 1.3fold) (Fig. 3). The differences in the basal Fos expression levels, especially in the cRPa, between the two stimulation experiments (Fig. 3) could be attributed to the effect of anesthesia: saline-injected rats were placed under urethane anesthesia, whereas $24^{\circ} \mathrm{C}$-exposed ones were awake. In VGLUT3-negative cells, a clear increase of Fos expression by these thermogenic stimuli was not observed in the medullary raphe regions tested, except for the $\mathrm{rRPa}$ (Fig. $2 c)$. In the $\mathrm{rRPa}$, the number of Fos-immunoreactive VGLUT3-negative cells was significantly increased by both stimuli; $76 \pm 24$ cells in salineinjected rats $(n=3)$ and $172 \pm 6$ in $\mathrm{PGE}_{2}$-injected rats $(n=4), p<$ $0.01 ; 64 \pm 11$ cells in $24^{\circ} \mathrm{C}$-exposed rats $(n=3)$ and $156 \pm 21$ in $4^{\circ} \mathrm{C}$-exposed rats $(n=3), p<0.05$.

Transneuronal retrograde labeling of VGLUT3-expressing medullary raphe neurons from sympathetically controlled thermoregulatory effector organs

To examine whether the VGLUT3-expressing medullary raphe neurons are located on the pathways that sympathetically regulate thermoregulatory effector organs, we performed transneuro- 
nal retrograde tracing studies by inoculation of PRV into the interscapular BAT or tail; the BAT is known as one of the major metabolically thermogenic organs in rodents especially during fever (Rothwell, 1992), and the rat tail functions as a heat loss organ by regulating the blood flow through vasoconstriction of blood vessels in its skin (Gordon, 1990). At 46-48 hr after inoculation into the BAT, PRV immunoreactivity was detected in neurons immunoreactive for ChAT, a marker for SPNs, in the IML on the side ipsilateral of injection (Fig. 4a), and these PRVinfected neurons were concentrated in the T2-T6 segments and sparsely distributed in segments T1 and T7. At this postinoculation time point, no infected cells were found in any other regions of the spinal cord, and within the medulla oblongata, there were very few. At 69-70 hr after inoculation into the BAT, many PRV-infected neurons were distributed over diverse brain regions in a similar way as observed in previous studies (Bamshad et al., 1999; Oldfield et al., 2002; Cano et al., 2003; Yoshida et al., 2003). Double immunofluorescence staining for VGLUT3 and PRV revealed PRV infection in many VGLUT3-expressing medullary raphe neurons (Figs. $4 c, 5 a$ ). In the $\mathrm{RMg}, \mathrm{PPy}, \mathrm{rRPa}$, and the ventral surface of the pyramidal tract, $60-80 \%$ of VGLUT3immunoreactive neurons were infected with PRV, whereas in the caudal medullary raphe regions ( $\mathrm{ROb}$, Giv, and $\mathrm{cRPa}$ ), $40-60 \%$ of them got infected (Table 1).

In rats inoculated with PRV into the tail, the emergence of PRV infection in the spinal cord and brain was delayed compared with inoculation into the BAT. At 96-98 hr after inoculation, only a few PRV-infected neurons were found in the medulla oblongata. At this time point, in the spinal cord, infection was detected in ChAT-immunoreactive neurons in the IML of the T10-L1 segments heavily on the side ipsilateral of inoculation and weakly on the contralateral side (Fig. 4b). PRV-infected cells in the dorsal or ventral horn were very few. At $121 \mathrm{hr}$ after inoculation, PRV-infected neurons were distributed in diverse regions of the brain with a distribution pattern similar to that shown in a previous report (Smith et al., 1998), and infection was found in VGLUT3immunoreactive medullary raphe neurons (Figs. $4 d, 5 b$ ). Although PRV infection in the ventral medulla at this time point was heavier than that at 69-70 hr after inoculation into the BAT, the extent of PRV infection in VGLUT3-immunoreactive neurons was not markedly different from that observed after inoculation into the BAT; $60-90 \%$ and $40-70 \%$ of VGLUT3-positive neurons were PRV infected in the rostral and caudal medullary raphe regions, respectively (Table 1).

\section{Direct projection of VGLUT3-expressing medullary raphe neurons onto SPNs}

We further examined the projections of the VGLUT3-expressing medullary raphe neurons by using a highly sensitive anterograde
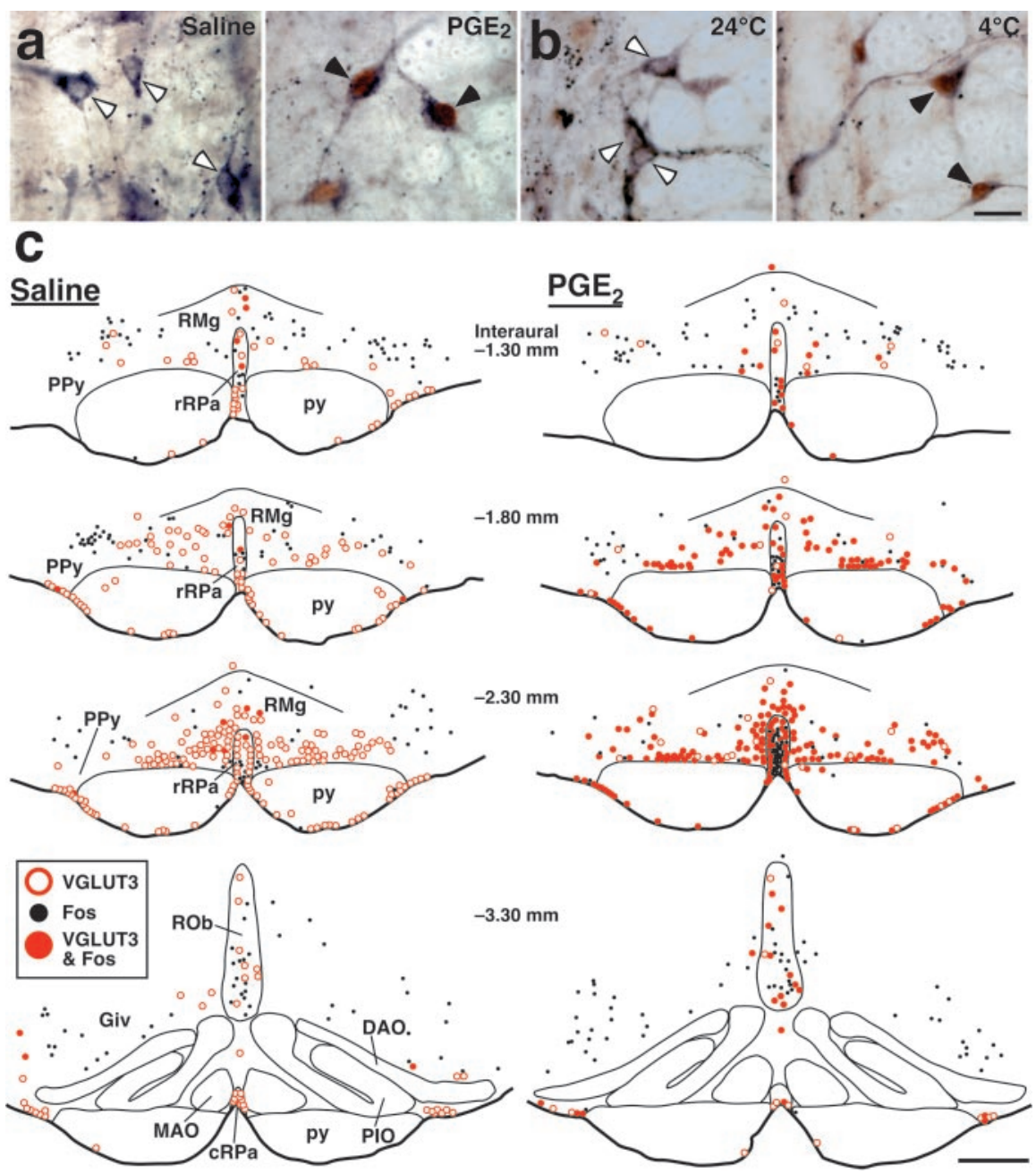

Figure 2. Fos expression in VGLUT3-immunoreactive medullary raphe neurons in response to central PGE 2 application and cold exposure. $a, b$, Double immunoperoxidase staining for VGLUT3 (blue-black) and Fos (brown) in the rRPa and RMg after intracereof

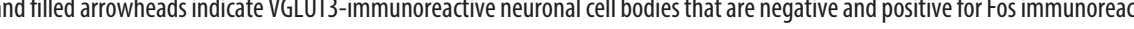
tivity, respectively. c, Brain maps showing the distribution of VGLUT3-immunoreactive neurons and Fos-immunoreactive cells. Immunoreactive cells in a 20 - $\mu \mathrm{m}$-thick frontal section of the corresponding rostrocaudal position were plotted on a drawing. Scale bars: $a, b$ (in $b$ ), $20 \mu \mathrm{m} ; c, 500 \mu \mathrm{m}$.

tracing technique that was developed by Furuta et al. (2001). This technique uses a replication-defective recombinant Sindbis virus that was designed for the infected cells to express a membranetargeted form of EGFP (Moriyoshi et al., 1996), enabling us to label the infected neurons in a Golgi stain-like manner. We injected the Sindbis virus into the rRPa and $\mathrm{RMg}$ at the rostrocaudal level of interaural $-2.30 \mathrm{~mm}$ (Fig. 6a), in which VGLUT3expressing neurons were most densely localized. In those cases in which infection was caused in VGLUT3-immunoreactive neurons (Fig. 6b), EGFP-positive axons were distributed in the IML throughout the thoracic cord. In the upper thoracic cord (T1T4), many EGFP-positive axons and terminals were densely localized in the IML, and their distribution overlapped well with that of VGLUT3-immunoreactive axon terminals (Fig. 6c). Triple immunofluorescence labeling and confocal laser-scanning microscopy visualized close apposition of axon swellings doublelabeled with EGFP and VGLUT3 immunoreactivities to ChATimmunoreactive dendrites in the IML in both upper (T1-T4) and lower (T10-T13) thoracic segments (Fig. 6d). 


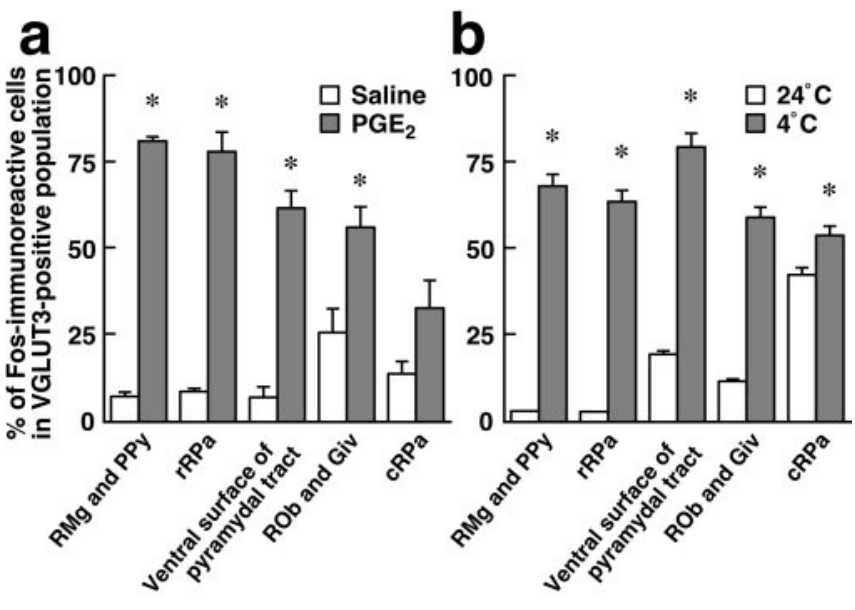

Figure 3. Quantitative analysis of Fos expression in VGLUT3-immunoreactive medullary raphe neurons in response to intracerebroventricular injection of saline (open bars; $n=3$ ) or $\mathrm{PGE}_{2}$ (shaded bars; $n=4)(a)$ and to exposure of rats to environmental temperature of $24^{\circ} \mathrm{C}$ (open bars; $n=3$ ) or $4^{\circ} \mathrm{C}$ (shaded bars; $\left.n=3\right)(b)$. The number of immunoreactive cells was counted in every six $20-\mu \mathrm{m}$-thick frontal sections of the medulla oblongata (see Fig. 2). Each bar represents the mean \pm SEM of the group. Asterisks indicate statistically significant differences between the $\mathrm{PGE}_{2}$ - and saline-injected groups or between the $4^{\circ} \mathrm{C}-$ and $24^{\circ} \mathrm{C}$-exposed groups $(p<0.05)$.

\section{Glutamatergic transmission mediates the BAT thermogenic pathway from rostral medullary raphe regions to the IML}

We next studied on the glutamate-mediated control of thermoregulatory effector organs, especially focusing on the interscapular BAT. Although it has been reported that microinjection of glutamate into the IML exerts an excitatory effect on cardiac functions (Sundaram et al., 1989), the effect on thermoregulatory effector organs has not yet been tested. As shown by the present PRV study, the subpopulation of SPNs sending outputs to the interscapular BAT are distributed mainly in the T2-T6 segments. Thus, we monitored the changes of $\mathrm{T}_{\mathrm{BAT}}$ after glutamate microinjection into the IML of these thoracic segments. In our preliminary experiments, $\mathrm{T}_{\mathrm{BAT}}$ changes after a single microinjection into the IML of the T4 segment were too subtle to be detected. Therefore, three microinjections were made in segments T3, T4, and T5 (one injection per segment). Such combined glutamate microinjections into the IML (Fig. $7 b, c$ ) caused a significant rise in $\mathrm{T}_{\mathrm{BAT}}\left(1.0 \pm 0.2^{\circ} \mathrm{C} ; n=3\right)$ compared with saline microinjections into the IML $\left(0.2 \pm 0.1^{\circ} \mathrm{C} ; n=3 ; p<0.005\right)$ (Fig. $\left.7 a\right)$. In contrast, glutamate microinjections into the dorsal or ventral horn caused no significant changes in $\mathrm{T}_{\text {BAT }}$ (Fig. $7 b$ ).

Based on the above results, we hypothesized that VGLUT3expressing medullary raphe neurons exert sympathetic premotor activities that maintain normothermic body temperature and produce fever. If this is the case, a sympathetic drive from rostral medullary raphe regions would exert thermogenic effects through its excitatory, probably glutamatergic, activity on SPNs. Thus, we next examined the effect of blockade of glutamatergic synapses in the IML on BAT thermogenesis triggered by stimulation of rostral medullary raphe regions. Consistent with the previous studies that disinhibition of $\mathrm{rRPa}$ and $\mathrm{RMg}$ neurons by bicuculline, a $\mathrm{GABA}_{\mathrm{A}}$ receptor antagonist, caused a rise in the sympathetic nerve activity to the BAT (Morrison, 1999; Morrison et al., 1999), bicuculline injection centered at the rRPa at the rostrocaudal level of interaural $-2.30 \mathrm{~mm}$ (Fig. $8 b, c$ ) reproducibly induced a rise in $\mathrm{T}_{\mathrm{BAT}}$ of $>2.5^{\circ} \mathrm{C}$. To block glutamatergic neurotransmission, we made injections of a mixture of AP-5, an NMDA receptor antagonist, and CNQX, an AMPA/kinate recep- tor antagonist, into the IML over the T2-T6 segments. The pretreatment with the glutamate receptor antagonists blocked the rise in $\mathrm{T}_{\mathrm{BAT}}$ triggered by bicuculline injection into the $\mathrm{rRPa}$ $\left(0.6 \pm 0.1^{\circ} \mathrm{C} ; n=4\right)$ (Fig. $\left.8 a\right)$. In rats injected with saline into the IML, intra-rRPa bicuculline injection caused a $\mathrm{T}_{\mathrm{BAT}}$ rise $(3.0 \pm$ $0.1^{\circ} \mathrm{C} ; n=3$ ) to the level observed in untreated rats (Fig. $8 a$ ). These results indicate that glutamatergic neurotransmission in the IML essentially mediates the thermogenic sympathetic pathway associated with the rostral medullary raphe regions.

\section{Discussion}

The rostral medullary raphe region consisting of the $\mathrm{rRPa}$ and $\mathrm{RMg}$ has been considered to mediate fever induction and other thermoregulatory functions. In the present study, we showed that neurons concentrated mainly in this raphe region expressed VGLUT3 and that Fos expression in medullary raphe regions in response to thermogenic stimuli (i.e., central $\mathrm{PGE}_{2}$ administration and cold exposure) occurred mostly in the VGLUT3expressing neuronal population, although the rRPa additionally contained a VGLUT3-negative/Fos-positive neuronal population. These results indicate that, in medullary raphe regions, VGLUT3-immunoreactive neurons constitute a major neuronal population that is stimulated for thermogenic responses to pyrogens and cold ambient temperature. As evidenced by the present PRV study, VGLUT3-expressing medullary raphe neurons are likely to multisynaptically innervate the interscapular BAT and the tail, which are thermogenic and heat loss organs, respectively, in rats. Furthermore, our anterograde neural tract tracing study revealed direct projections of VGLUT3-expressing medullary raphe neurons onto SPNs in both upper and lower thoracic cords, which are involved in the control of the interscapular BAT and tail, respectively. These results suggest that VGLUT3-expressing medullary raphe neurons mediate fever and other thermoregulatory functions through their direct adjustment of the activity of the SPNs controlling thermoregulatory effector organs. In addition, the clear association of a vast majority of the thermoregulatory medullary raphe neurons with VGLUT3 expression gives these neurons a fairly distinct phenotype and also proposes the possibility of VGLUT3 immunoreactivity as an indicator of these thermoregulatory neurons.

Although VGLUT3 has not yet been well established as a marker for glutamatergic neurons, this transporter has been shown to accumulate glutamate into vesicles (Fremeau et al., 2002; Gras et al., 2002; Schäfer et al., 2002; Takamori et al., 2002). Our recent immuno-electronmicroscopical study in the IML has revealed the localization of VGLUT3 immunoreactivity in clusters of synaptic vesicles in axon terminals that formed characteristic asymmetric synapses and were believed to excite SPNs (Nakamura et al., 2004). In addition, SPNs are known to express ionotropic glutamate receptors (McNair et al., 1998; Aicher et al., 2000). In the present study, glutamate applied into the IML produced BAT thermogenesis, and blockade of glutamatergic neurotransmission in the IML abolished BAT thermogenesis that was triggered by disinhibition of $\mathrm{rRPa}$ and $\mathrm{RMg}$ neurons, perhaps of VGLUT3-expressing neurons. These lines of evidence support the idea that VGLUT3-expressing medullary raphe neurons function as glutamatergic excitatory neurons that could be categorized as a novel group of sympathetic premotor neurons mediating fever and other thermoregulatory functions.

The present PRV study chose the postinoculation time that enabled us to observe the first infection wave, to minimize the infection to interneurons in the regions tested. Previous studies have examined PRV infection in various brain regions at several postin- 

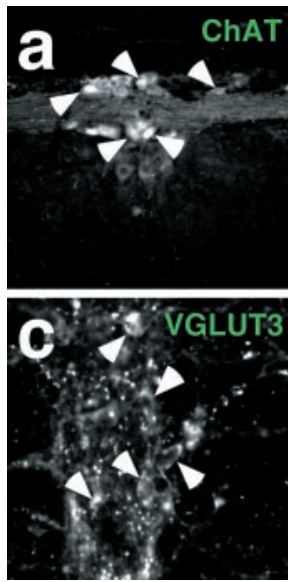
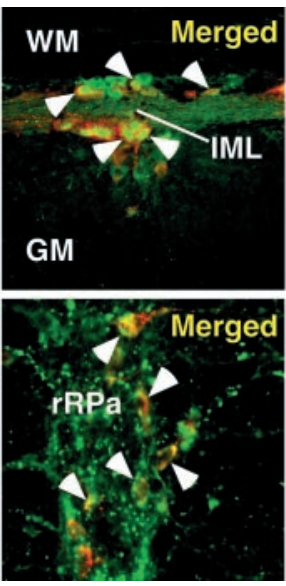
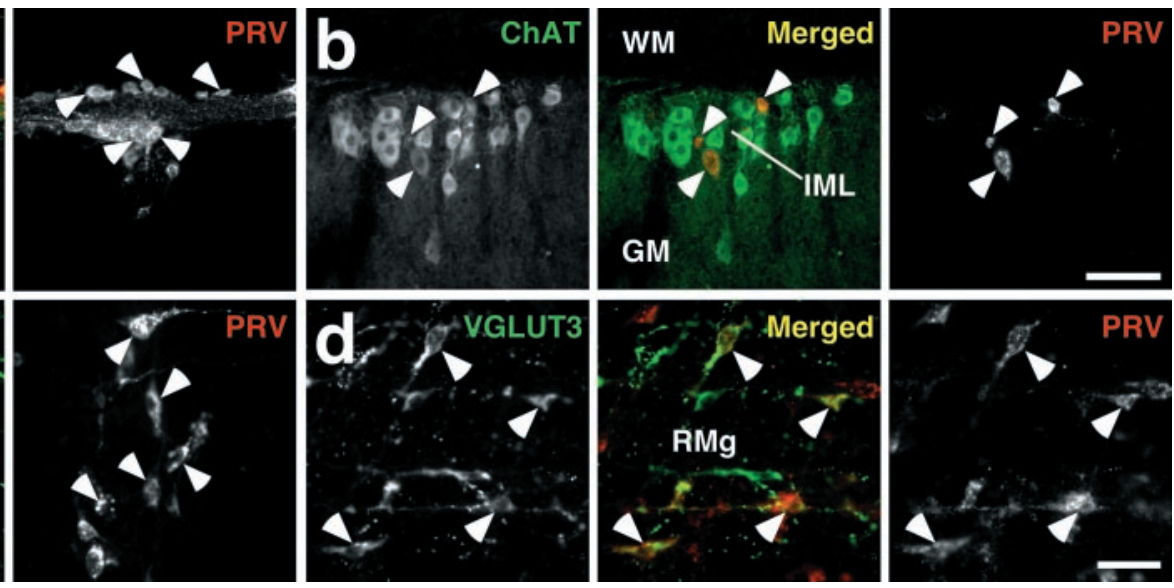

Figure 4. Retrograde transneuronal labeling with PRV inoculated into the interscapular BAT or the tail. $a, b$, Double immunofluorescence staining for ChAT (green) and PRV (red) in horizontal spinal cord sections of the T3 segment at $47 \mathrm{hr}$ after inoculation into the BAT $(a)$ and of the T12 segment at $98 \mathrm{hr}$ after inoculation into the tail (b). Arrowheads indicate PRV-infected ChATimmunoreactive neurons clustering in the IML. c, $d$, Double immunofluorescence staining for VGLUT3 (green) and PRV (red) in rostral medullary raphe regions in frontal sections at 69 hr after inoculation into the BAT $(c)$ and at $121 \mathrm{hr}$ after inoculation into the tail ( $($ ). The arrowheads indicate PRV-infected VGLUT3-immunoreactive neurons. GM, Gray matter; WM, white matter. Scale bars: $a, b$ (in $b), 100 \mu \mathrm{m} ; c, d$ (in $d), 50 \mu \mathrm{m}$.

oculation time points to estimate the order of infected neurons in descending pathways to SPNs (Smith et al., 1998; Bamshad et al., 1999; Oldfield et al., 2002; Cano et al., 2003; Yoshida et al., 2003). In these studies, medullary raphe regions were one of the regions that got infected earliest in the brain after inoculation. This suggests that the medullary raphe neurons infected with PRV at a short postinoculation time, as chosen in the present study, are in the order next to SPNs. In addition, the present PRV study showed that VGLUT3-expressing medullary raphe neurons contained subpopulations controlling the interscapular BAT and the tail. If these two subpopulations formed segregated groups, less than half of VGLUT3-expressing medullary raphe neurons would be infected in each case of the PRV inoculation into the interscapular BAT and the tail. In fact, however, a dominant population $(70 \%)$ got infected in these cases. Thus, at least a part of VGLUT3-expressing medullary raphe neurons could be involved in the simultaneous control of the BAT and tail through their innervations to distinct subpopulations of SPNs.

It was reported that PRV infection in medullary raphe regions after inoculation into the interscapular BAT occurred in both serotonergic and non-serotonergic neurons (Cano et al., 2003). In addition, serotonergic and non-serotonergic medullary raphe neurons are known to project to the spinal cord (Bowker et al., 1981; Skagerberg and Björklund, 1985). However, the present study showed that most VGLUT3-expressing medullary raphe neurons were negative for serotoninimmunoreactivity, consistent with our previous results that $80-90 \%$ of VGLUT3-immunoreactive axon terminals in the IML lacked serotonin (Nakamura et
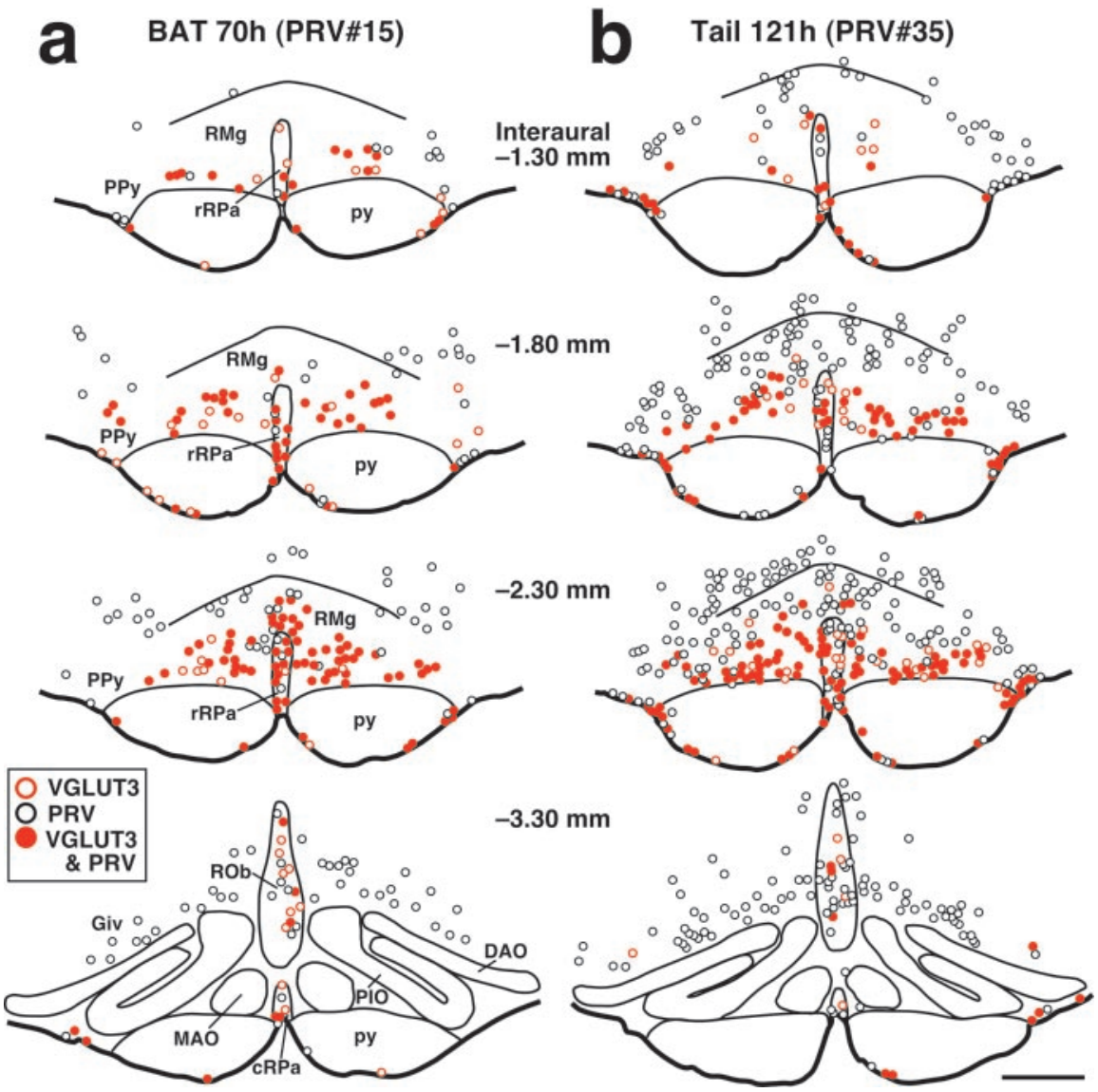

Figure 5. Brain maps showing the distribution of VGLUT3-immunoreactive neurons and PRV-immunoreactive ones at $70 \mathrm{hr}$ after inoculation into the interscapular BAT $(a)$ and at $121 \mathrm{hr}$ after inoculation into the tail $(b)$. Immunoreactive cell bodies in a 20 - $\mu \mathrm{m}$-thick frontal section of the corresponding rostrocaudal position were plotted on a drawing. PRV inoculation was made on the right side. Scale bar (in $b$ ), $500 \mu \mathrm{m}$.

al., 2004) and that most of the rRPa and RMg neurons that expressed Fos after central $\mathrm{PGE}_{2}$ administration were nonserotonergic (Nakamura et al., 2002). Furthermore, previous in vivo recordings from a cold-activated population of spinally projecting medullary raphe neurons showed that these neu- 
Table 1. Infection of VGLUT3-immunoreactive neurons with PRV

\begin{tabular}{|c|c|c|c|c|c|c|c|c|}
\hline \multirow[b]{3}{*}{ Regions } & \multicolumn{8}{|c|}{ PRV-infected cells/total VGLUT3-immunoreactive cells } \\
\hline & \multicolumn{4}{|l|}{ BAT } & \multicolumn{4}{|l|}{ Tail } \\
\hline & \multicolumn{2}{|c|}{ PRV\#15 (70 hr) } & \multicolumn{2}{|c|}{ PRV\#18 (69 hr) } & \multicolumn{2}{|c|}{ PRV\#34 (121 hr) } & \multicolumn{2}{|c|}{ PRV\#35 (121 hr) } \\
\hline RMg and PPy & $179 / 236$ & $(76 \%)$ & $164 / 245$ & $(67 \%)$ & $220 / 349$ & $(63 \%)$ & $203 / 304$ & $(67 \%)$ \\
\hline $\mathrm{rRPa}$ & $63 / 74$ & $(85 \%)$ & $56 / 84$ & $(67 \%)$ & $59 / 101$ & $(58 \%)$ & $48 / 75$ & $(64 \%)$ \\
\hline Ventral surface of pyramidal tract & 73/106 & $(69 \%)$ & $60 / 94$ & $(64 \%)$ & $183 / 215$ & $(85 \%)$ & $152 / 163$ & $(93 \%)$ \\
\hline ROb and Giv & $25 / 58$ & $(43 \%)$ & $26 / 41$ & $(63 \%)$ & $69 / 101$ & $(68 \%)$ & $39 / 105$ & $(37 \%)$ \\
\hline $\mathrm{CRPa}$ & $13 / 20$ & $(65 \%)$ & $9 / 20$ & $(45 \%)$ & $19 / 34$ & $(56 \%)$ & $17 / 32$ & $(53 \%)$ \\
\hline
\end{tabular}

PRV was inoculated into the interscapular BAT or tail, and the animals were allowed to survive for the period of time indicated. Every six 20 - $\mu$ m-thick frontal sections throughout the medulla oblongata were immunostained (see Fig. $4 c, d$ ) and examined for PRV immunoreactivity in VGLUT3-immunoreactive cells. Two representative cases each for inoculations into the BAT and tail are shown.
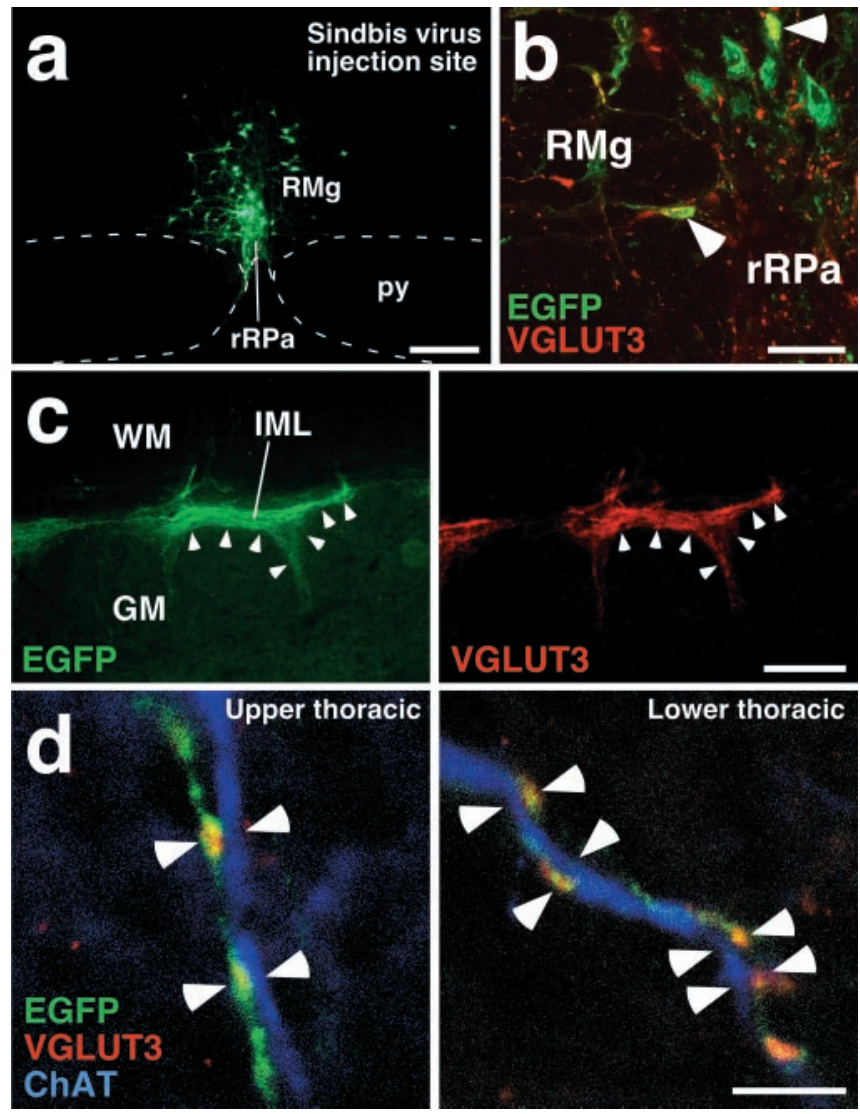

Figure 6. Direct projection of VGLUT3-immunoreactive medullary raphe neurons onto SPNs. $a$, Injection of recombinant Sindbis virus into the rRPa and RMg at the rostrocaudal level of interaural $-2.30 \mathrm{~mm}$. Infected cells expressed a membrane-targeted form of EGFP. $b$, Infection of VGLUT3-immunoreactive neurons with the Sindbis virus. There were neurons exhibiting both VGLUT3 immunoreactivity (red) and EGFP fluorescence (green) in the injection site (arrowheads).c, Double fluorescence microscopy for EGFP fluorescence and VGLUT3 immunoreactivity in a horizontal spinal cord section of the T3 segment. The right and left photomicrographs were taken at the same field under different excitations. EGFP-positive axon fibers and terminals were densely localized in the IML, and their distribution well overlapped that of VGLUT3immunoreactive terminals (arrowheads). $d$, Confocal laser-scanning microscopy of IML sections triple immunofluorescence-stained for EGFP (green), VGLUT3 (red), and ChAT (blue). Close apposition of axon swellings double-labeled with EGFP and VGLUT3 immunoreactivities to ChAT-immunoreactive dendrites (arrowheads) was found in both upper (T1-T4) and lower (T10-T13) thoracic segments. Scale bars: $a, 300 \mu \mathrm{m} ; b, 50 \mu \mathrm{m} ; c, 200 \mu \mathrm{m} ; d, 5 \mu \mathrm{m}$.

rons did not exhibit the electrophysiological properties of spinally projecting serotonergic neurons (Rathner et al., 2001). These findings suggest that excitatory raphe-spinal pathways mediating thermogenic signals are non-serotonergic.

We previously reported that the IML contained VGLUT2-
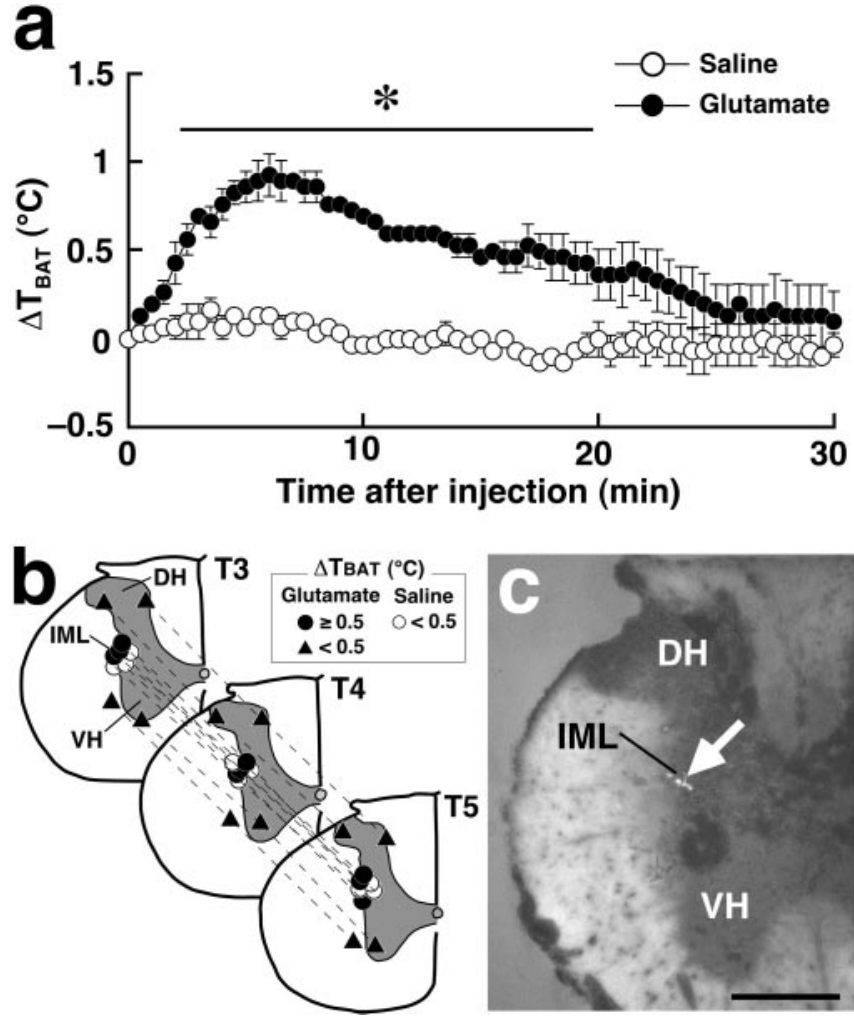

Figure 7. BAT thermogenesis induced by glutamate microinjection into the IML. $a$, Changes in temperature of the interscapular $B A T\left(\mathrm{~T}_{\mathrm{BAT}}\right)$ after saline or glutamate microinjections into the IML at three sites in segments $\mathrm{T} 3, \mathrm{~T} 4$, and $\mathrm{T} 5$ ( $b$, circles). $\mathrm{T}_{\mathrm{BAT}}$ was monitored at intervals of 30 sec. Each value represents the mean \pm SEM of three rats per group. The changes in $T_{B A T}$ were significantly different between the glutamate- and saline-injected groups during the time period denoted by a horizontal bar with an asterisk ( $p<0.05) . b$, Composite drawing of the effect of glutamate or saline microinjections into the thoracic spinal cord on $T_{B A T}$. Each symbol group tied with dotted lines corresponds to sites of microinjections made in one experiment and represents corresponding changes in $\mathrm{T}_{B A T} 30 \mathrm{~min}$ after the microinjections. C, A representative view of a site of intra-IML microinjection. The injection site is clearly identified as a small cluster of fluorescent beads (arrow) in the transverse section counterstained with toluidine blue. DH, Dorsal horn; VH, ventral horn. Scale bar, $500 \mu \mathrm{m}$.

and VGLUT3-immunoreactive axon terminals but lacked VGLUT1-immunoreactive ones (Nakamura et al., 2004). Because these VGLUT2- and VGLUT3-immunoreactive terminals formed segregated populations, the two types of terminals are likely provided by distinct neuronal populations (Nakamura et al., 2004). As shown in the present study, medullary raphe regions are an origin of the VGLUT3-positive terminals in the IML, and the VGLUT3-positive medullospinal projections likely mediate fever and other thermoregulatory functions. In contrast, VGLUT2 does not seem to be expressed in most medullary raphe 


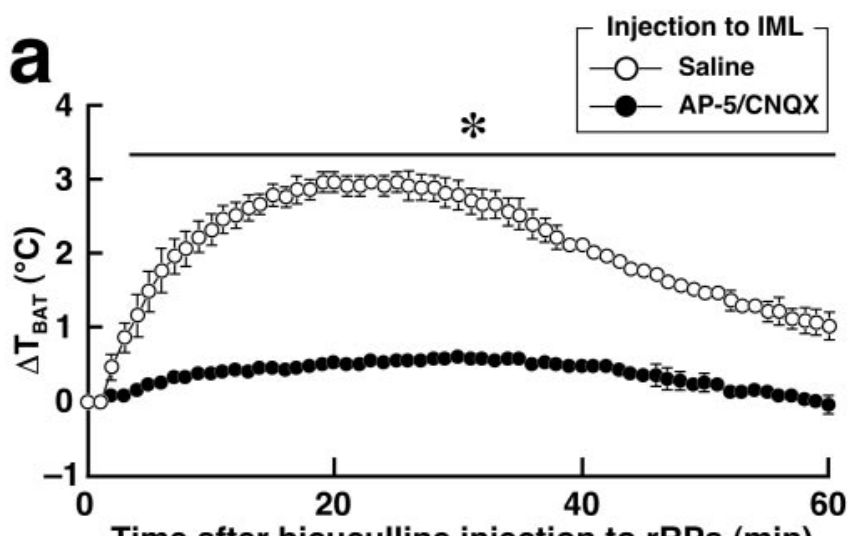

Time after bicuculline injection to $\mathrm{rRPa}(\mathrm{min})$

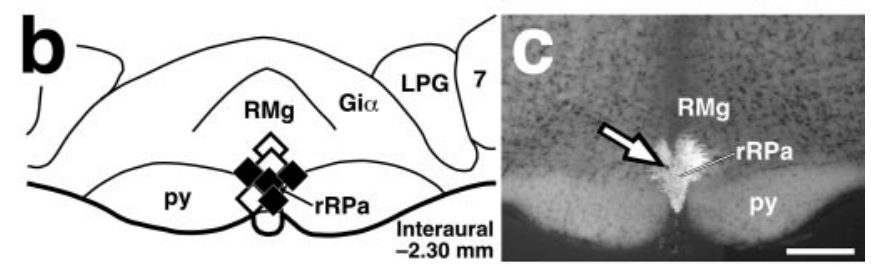

Figure 8. Microinjections of glutamate receptor antagonists into the IML block BAT thermogenesis triggered by bicuculline-induced disinhibition of rostral medullary raphe neurons. $a$ Changes in $\mathrm{T}_{\mathrm{BAT}}$ after bicuculline injection into the rRPa in rats microinjected with a mixture of AP-5 and CNQX $(n=4)$ or saline $(n=3)$ into the IML over the T2-T6 segments. $\mathrm{T}_{\text {BAT }}$ was monitored at intervals of $1 \mathrm{~min}$. Each value represents the mean $\pm \mathrm{SEM}$ of the group. The changes in $\mathrm{T}_{\mathrm{BAT}}$ were significantly different between the AP-5/CNQX- and saline-pretreated groups during the time period denoted by a horizontal bar with an asterisk ( $p<0.05)$. $b$, The position of the bicuculline (filled diamonds) and saline (open diamonds) injections made in $a . c$, A representative view of a site of intra-rRPa injection at the level of interaural $-2.30 \mathrm{~mm}$. The injection site is clearly identified as a cluster of fluorescent beads (arrow) in the section counterstained with toluidine blue. 7, Facial nucleus; $\mathrm{Gi} \alpha$, alpha part of the gigantocellular reticular nucleus; LPG, lateral paragigantocellular nucleus. Scale bar, $500 \mu \mathrm{m}$.

regions (Stornetta et al., 2002a), but its mRNA was shown to be expressed by vasomotor RVLM neurons that project to the thoracic spinal cord (Stornetta et al., 2002b). Thus, it is likely that the VGLUT2-positive terminals in the IML are derived from the RVLM and mediate RVLM-specific cardiovascular signals onto SPNs. The VGLUT3-positive terminals appear to be unrelated with the RVLM-mediated cardiovascular regulation because VGLUT3-immunoreactive neurons were found only occasionally in the RVLM. However, VGLUT3-expressing rostral medullary raphe neurons might be involved in cardiovascular responses (tachycardia and blood pressure increase) to specific cues, such as pyrogen and stress, as suggested by several reports. It was shown that bicuculline injection into the rRPa increased cardiac sympathetic activities (Samuels et al., 2002; Cao and Morrison, 2003) and that injection of muscimol, a $\mathrm{GABA}_{\mathrm{A}}$ receptor agonist, into this region blocked cardiovascular responses to central $\mathrm{PGE}_{2}$ application (Morrison, 2003) or to stress (Zaretsky et al., 2003) but had no effect on heart rate under basal conditions or on baroreflex responses $(\mathrm{Za}-$ retsky et al., 2003). These findings indicate a clear contrast between the sympathetic functions that could be mediated by VGLUT2- and VGLUT3-positive medullospinal projections.

The present results indicate that the activity control of VGLUT3expressing medullary raphe neurons would be made by signals from pyrogen- and thermo-reception systems. In pyrogen- and thermoreception, the preoptic area (POA) plays an important role. In this region, $\mathrm{PGE}_{2}$ acts as a powerful endogenous pyrogenic mediator (Feldberg and Saxena, 1971; Stitt, 1973; Williams et al., 1977; Scammell et al., 1996) and the EP3 subtype of PGE receptor is localized on the soma and dendrites of neurons (Nakamura et al., 1999). Furthermore, this PGE receptor subtype is essential for $\mathrm{PGE}_{2}$-induced fever (Ushikubi et al., 1998). Thus, $\mathrm{PGE}_{2}$ is considered to act on the EP3 receptor of POA neurons and trigger fever. The POA is also known as one of the major central thermosensitive sites to monitor deep body temperature: cooling of this region causes nonshivering thermogenesis (Banet et al., 1978; Imai-Matsumura et al., 1984), possibly as a result of suppression of warmsensitive neurons (Chen et al., 1998).

We have reported that pyrogenic $\mathrm{PGE}_{2}$ signals from the POA are mediated by rostral medullary raphe regions possibly through a direct projection from EP3 receptor-expressing POA neurons (Nakamura et al., 2002; Yoshida et al., 2003). In addition, another pathway through the dorsomedial hypothalamic nucleus was also proposed to transmit POA-derived pyrogenic $\mathrm{PGE}_{2}$ signals ( $\mathrm{Za}-$ retskaia et al., 2003). Other reports showed that warming of the POA abolished BAT thermogenesis evoked by stimulation of a hypothalamic region (Chen et al., 1998) and that this inhibitory effect by POA warming was antagonized by bicuculline injection into the raphe pallidus nucleus (Taniguchi et al., 2003). These findings suggest that the pyrogenic and heat-gain signals from the POA are conveyed to rostral medullary raphe regions and activate VGLUT3-expressing neurons therein. In the present study, bicuculline-induced disinhibition in the rRPa and RMg caused intense BAT thermogenesis, as reported previously by Morrison et al. (1999), suggesting that thermoregulatory medullary raphe neurons tonically receive GABAergic inhibitory inputs. Thus, the control of these tonic GABAergic inputs might be a key mechanism for the regulation of VGLUT3-expressing medullary raphe neurons by pyrogen- and thermo-reception systems.

The VGLUT3-expressing medullary raphe neurons identified in the present study are likely to mediate not only the basal regulation of body temperature but also sympathetic responses to external stress including infection. Furthermore, the thermoregulatory sympathetic activity of these neurons would additionally affect energy metabolism. Thus, a better understanding of VGLUT3-expressing medullary raphe neurons may provide us with tactics against diseases associated with metabolic dysfunction, such as obesity and diabetes. The sympathetic functions that could be mediated by VGLUT3-expressing medullary raphe neurons represent a striking contrast to the cardiovascular functions of the well established sympathetic premotor neurons in the RVLM. Although it is unknown whether there are subpopulations controlling specific effector organs in these sympathetic premotor neurons, the selectivity of sympathetic premotor pathways for the activation of effector organs would be important for the precise and well organized control of diverse sympathetic functions, which is essential for the adaptation of animals to drastic and quick environmental changes.

\section{References}

Aicher SA, Hahn B-I, Milner TA (2000) N-methyl-D-aspartate-type glutamate receptors are found in post-synaptic targets of adrenergic terminals in the thoracic spinal cord. Brain Res 856:1-11.

Bamshad M, Song CK, Bartness TJ (1999) CNS origins of the sympathetic nervous system outflow to brown adipose tissue. Am J Physiol 276:R1569-R1578.

Banet M, Hensel H, Liebermann H (1978) The central control of shivering and non-shivering thermogenesis in the rat. J Physiol (Lond) 283:569-584.

Blessing WW, Nalivaiko E (2001) Raphe magnus/pallidus neurons regulate tail but not mesenteric arterial blood flow in rats. Neuroscience 105:923-929. 
Blessing WW, Yu YH, Nalivaiko E (1999) Raphe pallidus and parapyramidal neurons regulate ear pinna vascular conductance in the rabbit. Neurosci Lett 270:33-36.

Bonaz B, Taché Y (1994) Induction of Fos immunoreactivity in the rat brain after cold-restraint induced gastric lesions and fecal excretion. Brain Res 652:56-64.

Bowker RM, Westlund KN, Coulter JD (1981) Origins of serotonergic projections to the spinal cord in rat: an immunocytochemical-retrograde transport study. Brain Res 226:187-199.

Cano G, Passerin AM, Schiltz JC, Card JP, Morrison SF, Sved AF (2003) Anatomical substrates for the central control of sympathetic outflow to interscapular adipose tissue during cold exposure. J Comp Neurol 460:303-326.

Cao W-H, Morrison SF (2003) Disinhibition of rostral raphe pallidus neurons increases cardiac sympathetic nerve activity and heart rate. Brain Res 980:1-10.

Chen X-M, Hosono T, Yoda T, Fukuda Y, Kanosue K (1998) Efferent projection from the preoptic area for the control of non-shivering thermogenesis in rats. J Physiol (Lond) 512:883-892.

Dampney RAL (1994) Functional organization of central pathways regulating the cardiovascular system. Physiol Rev 74:323-364.

Feldberg W, Saxena PN (1971) Further studies on prostaglandin $E_{1}$ fever in cats. J Physiol (Lond) 219:739-745.

Fremeau Jr RT, Burman J, Qureshi T, Tran CH, Proctor J, Johnson J, Zhang H, Sulzer D, Copenhagen DR, Storm-Mathisen J, Reimer RJ, Chaudhry FA, Edwards RH (2002) The identification of vesicular glutamate transporter 3 suggests novel modes of signaling by glutamate. Proc Natl Acad Sci USA 99:14488-14493.

Furuta T, Tomioka R, Taki K, Nakamura K, Tamamaki N, Kaneko T (2001) In vivo transduction of central neurons using recombinant Sindbis virus: Golgi-like labeling of dendrites and axons with membrane-targeted fluorescent proteins. J Histochem Cytochem 49:1497-1507.

Gordon CJ (1990) Thermal biology of the laboratory rat. Physiol Behav 47:963-991.

Gras C, Herzog E, Bellenchi GC, Bernard V, Ravassard P, Pohl M, Gasnier B, Giros B, El Mestikawy S (2002) A third vesicular glutamate transporter expressed by cholinergic and serotoninergic neurons. J Neurosci 22:5442-5451.

Hioki H, Fujiyama F, Nakamura K, Wu S-X, Matsuda W, Kaneko T (2004) Chemically specific circuit composed of vesicular glutamate transporter 3- and preprotachykinin B-producing interneurons in the rat neocortex. Cereb Cortex, in press.

Imai-Matsumura K, Matsumura K, Nakayama T (1984) Involvement of ventromedial hypothalamus in brown adipose tissue thermogenesis induced by preoptic cooling in rats. Jpn J Physiol 34:939-943.

Kaneko T, Fujiyama F (2002) Complementary distribution of vesicular glutamate transporters in the central nervous system. Neurosci Res $42: 243-250$.

Loewy AD (1981) Raphe pallidus and raphe obscurus projections to the intermediolateral cell column in the rat. Brain Res 222:129-133.

Madorin WS, Calaresu FR (1994) Cardiovascular changes elicited by microinjection of glycine or GABA into the spinal intermediolateral nucleus in urethane-anesthetized rats. Brain Res 634:13-19.

McAllen RM (1986a) Location of neurones with cardiovascular and respiratory function, at the ventral surface of the cat's medulla. Neuroscience $18: 43-49$

McAllen RM (1986b) Action and specificity of ventral medullary vasopressor neurones in the cat. Neuroscience 18:51-59.

McAllen RM, Neil JJ, Loewy AD (1982) Effects of kainic acid applied to the ventral surface of the medulla oblongata on vasomotor tone, the baroreceptor reflex and hypothalamic autonomic responses. Brain Res 238:65-76.

McNair CJ, Baxter GJ, Kerr R, Maxwell DJ (1998) Glutamate receptor subunits associated with rat sympathetic preganglionic neurons. Neurosci Lett 256:29-32.

Moriyoshi K, Richards LJ, Akazawa C, O’Leary DDM, Nakanishi S (1996) Labeling neural cells using adenoviral gene transfer of membranetargeted GFP. Neuron 16:255-260.

Morrison SF (1999) RVLM and raphe differentially regulate sympathetic outflows to splanchnic and brown adipose tissue. Am J Physiol 276:R962-R973.
Morrison SF (2003) Raphe pallidus neurons mediate prostaglandin $E_{2}$ evoked increases in brown adipose tissue thermogenesis. Neuroscience 121:17-24.

Morrison SF, Sved AF, Passerin AM (1999) GABA-mediated inhibition of raphe pallidus neurons regulates sympathetic outflow to brown adipose tissue. Am J Physiol 276:R290-R297.

Nakamura K, Kaneko T, Yamashita Y, Hasegawa H, Katoh H, Ichikawa A, Negishi M (1999) Immunocytochemical localization of prostaglandin EP3 receptor in the rat hypothalamus. Neurosci Lett 260:117-120.

Nakamura K, Kaneko T, Yamashita Y, Hasegawa H, Katoh H, Negishi M (2000) Immunohistochemical localization of prostaglandin EP3 receptor in the rat nervous system. J Comp Neurol 421:543-569.

Nakamura K, Li Y-Q, Kaneko T, Katoh H, Negishi M (2001) Prostaglandin EP3 receptor protein in serotonin and catecholamine cell groups: a double immunofluorescence study in the rat brain. Neuroscience 103:763-775.

Nakamura K, Matsumura K, Kaneko T, Kobayashi S, Katoh H, Negishi M (2002) The rostral raphe pallidus nucleus mediates pyrogenic transmission from the preoptic area. J Neurosci 22:4600-4610.

Nakamura K, Wu S-X, Fujiyama F, Okamoto K, Hioki H, Kaneko T (2004) Independent inputs by VGLUT2- and VGLUT3-positive glutamatergic terminals onto rat sympathetic preganglionic neurons. NeuroReport 15:431-436.

Oldfield BJ, Giles ME, Watson A, Anderson C, Colvill LM, McKinley MJ (2002) The neurochemical characterisation of hypothalamic pathways projecting polysynaptically to brown adipose tissue in the rat. Neuroscience 110:515-526.

Paxinos G, Watson C (1998) The rat brain in stereotaxic coordinates, Ed 4. San Diego: Academic.

Rathner JA, McAllen RM (1999) Differential control of sympathetic drive to the rat tail artery and kidney by medullary premotor cell groups. Brain Res 834:196-199.

Rathner JA, Owens NC, McAllen RM (2001) Cold-activated raphe-spinal neurons in rats. J Physiol (Lond) 535:841-854.

Rothwell NJ (1992) Eicosanoids, thermogenesis and thermoregulation. Prostaglandins Leukot Essent Fatty Acids 46:1-7.

Sagar SM, Sharp FR, Curran T (1988) Expression of $c$-fos protein in brain: metabolic mapping at the cellular level. Science 240:1328-1331.

Samuels BC, Zaretsky DV, DiMicco JA (2002) Tachycardia evoked by disinhibition of the dorsomedial hypothalamus in rats is mediated through medullary raphe. J Physiol (Lond) 538:941-946.

Scammell TE, Elmquist JK, Griffin JD, Saper CB (1996) Ventromedial preoptic prostaglandin $\mathrm{E}_{2}$ activates fever-producing autonomic pathways. J Neurosci 16:6246-6254.

Schäfer MK-H, Varoqui H, Defamie N, Weihe E, Erickson JD (2002) Molecular cloning and functional identification of mouse vesicular glutamate transporter 3 and its expression in subsets of novel excitatory neurons. J Biol Chem 277:50734-50748.

Skagerberg G, Björklund A (1985) Topographic principles in the spinal projections of serotonergic and non-serotonergic brainstem neurons in the rat. Neuroscience 15:445-480.

Smith JE, Jansen ASP, Gilbey MP, Loewy AD (1998) CNS cell groups projecting to sympathetic outflow of tail artery: neural circuits involved in heat loss in the rat. Brain Res 786:153-164.

Stitt JT (1973) Prostaglandin $\mathrm{E}_{1}$ fever induced in rabbits. J Physiol (Lond) 232:163-179.

Stornetta RL, Sevigny CP, Guyenet PG (2002a) Vesicular glutamate transporter DNPI/VGLUT2 mRNA is present in $\mathrm{C} 1$ and several other groups of brainstem catecholaminergic neurons. J Comp Neurol 444:191-206.

Stornetta RL, Sevigny CP, Schreihofer AM, Rosin DL, Guyenet PG (2002b) Vesicular glutamate transporter DNPI/VGLUT2 is expressed by both C1 adrenergic and nonaminergic presympathetic vasomotor neurons of the rat medulla. J Comp Neurol 444:207-220.

Sundaram K, Murugaian J, Sapru H (1989) Cardiac responses to the microinjections of excitatory amino acids into the intermediolateral cell column of the rat spinal cord. Brain Res 482:12-22.

Takamori S, Malherbe P, Broger C, Jahn R (2002) Molecular cloning and functional characterization of human vesicular glutamate transporter 3 . EMBO Rep 3:798-803.

Tamamaki N, Nakamura K, Furuta T, Asamoto K, Kaneko T (2000) Neu- 
rons in Golgi-stain-like images revealed by GFP-adenovirus infection in vivo. Neurosci Res 38:231-236.

Taniguchi A, Chen X-M, Nagashima K, Tanaka M, Kanosue K (2003) Involvement of the raphe pallidus in the suppressive effect of preoptic warming on non-shivering thermogenesis in rats. Brain Res 966:103-109.

Ushikubi F, Segi E, Sugimoto Y, Murata T, Matsuoka T, Kobayashi T, Hizaki H, Tuboi K, Katsuyama M, Ichikawa A, Tanaka T, Yoshida N, Narumiya $S$ (1998) Impaired febrile response in mice lacking the prostaglandin $\mathrm{E}$ receptor subtype EP3. Nature 395:281-284.

Williams JW, Rudy TA, Yaksh TL, Viswanathan CT (1977) An extensive exploration of the rat brain for sites mediating prostaglandin-induced hyperthermia. Brain Res 120:251-262.
Yoshida K, Nakamura K, Matsumura K, Kanosue K, König M, Thiel H-J, Boldogköi Z, Toth I, Roth J, Gerstberger R, Hübschle T (2003) Neurons of the rat preoptic area and the raphe pallidus nucleus innervating the brown adipose tissue express the prostaglandin E receptor subtype EP3. Eur J Neurosci 18:1848-1860.

Zaretskaia MV, Zaretsky DV, DiMicco JA (2003) Role of the dorsomedial hypothalamus in thermogenesis and tachycardia caused by microinjection of prostaglandin $\mathrm{E}_{2}$ into the preoptic area in anesthetized rats. Neurosci Lett 340:1-4.

Zaretsky DV, Zaretskaia MV, Samuels BC, Cluxton LK, DiMicco JA (2003) Microinjection of muscimol into raphe pallidus suppresses tachycardia associated with air stress in conscious rats. J Physiol (Lond) 546:243-250. 